\title{
The Role of Pictorial Metaphor in Magazine Advertising
}

\author{
Victoria Martín de la Rosa \\ Complutense University of Madrid \\ mvmartin@filol.ucm.es
}

\begin{abstract}
Most studies on metaphor, in the wake of the work published by Lakoff and Johnson (1980), have mainly focused on its verbal component. Few scholars have attempted to approach the study of metaphor from the perspective of its non-verbal manifestations. Among them, I will mention Forceville $(1994,1996)$, who has done extensive research into the use of what he has coined "pictorial metaphor" and has provided an interesting account of it in the domain of advertising. In this paper, following the example set by this author, I consider a number of pictorial metaphors with some of the same guiding questions: What is the literal A-term? What is the figurative B-term? And what properties get projected from one onto the other? The concept of situational context (Fairclough, 1989) will play a key role when answering these questions. Finally, presuming that language is "an instrument of control" as claimed by Hodge and Kress (1993), I will try to uncover the persuasion exercised through metaphor (its inference patterns and value judgements) in the discourse of advertising.
\end{abstract}

\section{Introduction}

Not only has the study of metaphor been one of the main subjects of inquiry within the fields of literature and psychology, but it has also been within linguistics -our primary concern-. The interest in this topic, indeed, has been pursued and revived of late by the work of cognitive linguists such as Lakoff and Johnson, who, with the publication of their work Metaphors we live by (1980), have given this device a new impetus by presenting it in a new light. Henceforth, metaphor would be defined as a cognitive device which allows us to deal with abstract domains of experience by understanding and experiencing one thing in terms of 
another, which implies that it pervades our use of language, as a reflection of our thinking, no matter how unaware we are of it or how hard we try to avoid it. Later contributions by the same authors to the theory of metaphor can be found in Lakoff's publication on the analysis of contemporary American politics (1996) and Lakoff and Johnson's book (1999) on the analysis of Western philosophy. Both publications work on redefining the structure of the two concepts by applying this new vision of metaphor. This redefinition, which was at odds with the view held by many of the scholars dating from Antiquity up to the $20^{\text {th }}$ century, served as a catalyst for many of the books and articles that have been written on the subject since. Metaphor has been approached from the verbal point of view; that is to say, the object of study has been utterances that render metaphor in a given type of discourse. In this paper, though, I intend to study metaphor from the perspective of both its nonverbal and verbal manifestations. Thus, I shall be discussing the use of pictorial metaphors (term coined by Forceville, 1994) throughout this paper; in other words, the use of those metaphors found in pictures.

Unlike verbal metaphor, only few scholars (e.g. Kennedy, 1982; Hausman, 1989; Whittock, 1990; Forceville, 1994, 1996) have devoted attention to this topic. I will now briefly mention the work done by two of them, Kennedy and Forceville, as some of the concepts and questions behind their analysis will turn out to be relevant to my study.

In the case of Kennedy, he studied metaphor in pictures by applying Richards' (1971) well-known concepts of tenor (primary subject) and vehicle (secondary subject). Thus, an example such as "life is a journey" has life as tenor and journey as vehicle. Nevertheless, there is a difference between Kennedy and Richards' interpretation of metaphor. Whereas Kennedy (1982: 593) uses metaphor as "a general term applying to many kinds of figures of speech", Richards, on the other hand, uses this concept in a more restricted manner, more in the fashion used today, as can be seen in the following words: "the co-presence of the vehicle and tenor results in a meaning [...] which is not attainable without their interaction" (1971: 100).

As far as Forceville $(1994,1996)$ is concerned, he is the first one to introduce a comprehensive theory of pictorial metaphor in advertising which offers a useful model for analysis. He proposes that pictorial metaphor, the same as its verbal version, has two terms: a "literal primary subject" and a "figurative secondary subject" (1996: 5). In each metaphor, there is a mapping of one or more features of the domain of the secondary subject ("source domain") onto the domain of the primary subject ("target domain"). He specifically mentioned three questions that are to be asked to test if we are really facing a metaphor: "What are the two terms of the metaphor and how do we know? Which of the two terms is the ("literal") A-term and which is the ("figurative") B-term? And what can be said about the transfer of properties from B to A?" (1994: 2). Reference to his work is inevitable as in this paper I analyze the same type of discourse (advertisements) with an eye on the same type of cognitive device: pictorial metaphor.

In the case of advertising, the fundamental goal is to highlight a number of attributes so that consumers feel attracted into buying the product. Precisely the way to emphasize those values is through the establishment of a number of mappings which project features from the source domain onto the target domain; or in other words, by creating a link between the product advertised (target domain) and an image (the source domain) where the product 
inherits the qualities and emotional values assigned to the image. In the process the consumer is invited to take part in the meaning creation of the product, which implies that the conceptualization of the product in terms of another entity is an active process in which not only the advertiser but the consumer is also involved.

As for the hypothesis guiding this paper, I maintain that the use of pictorial metaphor contributed to a more effective and visual transmission of a number of values promoted by the purchase of a product or use of a service. Thus, going back to the claim of the persuasive power of metaphors, one of the important functions of metaphors is to manipulate readers' minds through the inference patterns and value judgments generated by the metaphors being used.

The study will proceed by analyzing a number of Spanish advertisements (reproduced here) taken from advertising magazines. The reason behind the choice of advertisements is that they have a very straight forward purpose directing our attention persuasively to certain aspects of experience and hiding others, which is the point highlighted by Barthes (1986) when he says that intentionality is a key ingredient in advertising as only the attributes that want to be transmitted get all the light and attention.

\section{Conceptual framework}

The present discussion, following the example set by Forceville, will be developed by relying mostly on the vocabulary which has originated from studies in the domain of verbal metaphor, as it is in that area that metaphor has been extensively researched. Thus, the assumptions resulting from studies on verbal metaphor and guiding this analysis are the ones that follow: Firstly, the view of metaphor taken in this paper is the one illustrated by Lakoff and Johnson (1980), as presented above, where metaphor is taken as a cognitive mechanism which only derivatively gets reflected into language. Following Forceville (1996), I will be presenting how metaphor, apart from its verbal manifestations, can also occur in pictures, more particularly, printed adverts.

Secondly, as a general framework I follow Black's new interaction view as presented in Ortony (1993:27-28), which is a development of Richard's insights into the role of metaphor. The main lines of Black's theory can be reproduced in the following five claims: first, a metaphorical statement has two distinct subjects, identified as the primary and the secondary subject; second, the secondary subject is to be regarded as a system rather than an individual thing; third, the metaphorical utterance works by "projecting upon" the primary subject a set of "associated implications," comprised in the implicative complex, that are predicable of the secondary subject; fourth, the maker of a metaphorical statement selects, emphasizes, suppresses, and organizes features of the primary subject by applying to it statements isomorphic with the members of the secondary subject's implicative complex; fifth, in the context of a particular metaphorical statement, the two subjects "interact" in the following ways: (a) the presence of the primary subject incites the hearer to select some of the secondary subject's properties; (b) invites him to construct a parallel implication-complex that can fit the primary subject; and (c) reciprocally induces parallel changes in the secondary subject. I also 
take Black's claim (1993) that metaphors tend to create the similarity between the domains involved rather than reproduce a similarity that was already there in the first place to be of the utmost relevance for the present paper. ${ }^{1}$ In line with the importance of similarity, physical resemblance, spatial resemblance and resemblance related to size will be especially important in pictorial metaphor as will be seen throughout this study.

Thirdly, within our framework of cognitive grammar, a notion of particular relevance will be that of ideology considered "as a systematic body of ideas, organized from a particular point of view" (Hodge and Kress, 1993: 6) since language is considered a tool to manipulate while conveying information. This means, that while hearers are supposedly being informed they are, at the same time, being manipulated, without being aware of it, through the way issues are presented. Cognitive grammar works as a frame that plays an important role providing insight into language uses through one of the cognitive resources of human language: metaphor. Thus, this approach should be of great utility in an analysis that tries to unveil the manipulation of human language through the persuasive power of metaphors when it comes to carrying out certain social and political goals.

Fourthly, another important concept will be that of context. Fairclough (1989) calls it situational context, which implies that the interpretation of a certain text is heavily dependent on context, which implies that to assign meaning to a given text, the verbal/pictorial element is not enough and the assumptions and world knowledge of the interpreter must be brought into the picture. Pushing in the same direction, though in the domain of pictures, we find the claim by Kennedy (1982: 604) when he says that depiction does not offer unequivocal information but "rather the depiction operates because the various pictorial effects are selected by the viewer, not because the external display is specific and unambiguous".

Finally in the list of assumptions, I rely on the work by Roland Barthes (1986) in order to address the verbal component in advertisements. He discusses the existence of three types of messages: the linguistic message, the denoted message and the connoted message. As for the linguistic message, it refers to the textual element of the message "whether it appears "as caption, as a headline, as a press article, as a film dialogue as a comic-strip balloon;" (1986: 27). The two functions of the linguistic message from less to more frequent are: relaying and anchoring. The linguistic message in this second function guides the viewer towards correctly interpreting the pictorial elements of the image. In his words, "the text directs the reader among the various signifieds of the image, and causes him to avoid some and to accept others" (1986: 29). As for the pictorial side of the advertisement, he distinguished between the connoted message, which is the image charged with all the symbolic connotations viewers bring to bear, and the denoted message, which is what remains once the signs of connotation have been deleted. Nevertheless, he made it clear that this distinction is just made on practical terms as they together permeate the entire image.

As pointed out by Forceville (1994), it must not be forgotten that since we are applying all this body of knowledge arising from the study of verbal metaphor on pictorial metaphor, a good amount of imagination -one important tenet of cognitive linguistics- will be needed as instead of having metaphors materialized in utterances we shall see them reflected in pictures. In the next section, I start the analysis of the advertisements selected by applying the theoretical apparatus mentioned so far. 


\section{Analysis of advertisements}

The present analysis, which focuses on the values promoted of a number of products among the members of our community, uses four print advertisements appeared in magazines that contain pictorial metaphors. Thus, they can be reproduced entirely almost in their original form. Besides, the choice of print adverts is ideal because the use of pictorial metaphor is a very frequent device in this type of discourse.

The method adopted here is based on Forceville $(1994,1996)$. Following his procedure, firstly I assume that pictorial metaphor has two terms: a literal primary subject and a figurative secondary subject; and secondly the criteria employed to assess metaphor identification previously mentioned in the introductory section - answer the following questions: 1) What are the two terms of the metaphor?; 2) Which of the two terms is the (literal) A-term and which is the (figurative) B-term?; and 3) what features are mapped from B to A?

With those parameters in mind, let us proceed to the analysis of the different advertisements.

\subsection{BURGERBRA Advertisement}

The choice of this advertisement is based mainly on the fact that its text is mainly pictorial with a very short textual message, though, as will be seen later, its use is vital to the understanding of the message.



Figure 1. 
The objects in the foreground are two burgers. By looking at the pictorial context, we understand the viewer is invited to see a burger not in its literal sense but in terms of something else: a BOSOM. But let us look at the process resulting in the metaphor A BURGUER IS BOSOM. To answer this question I shall address several questions following Forceville (1994, 1996), as commented in what follows.

Firstly, how do we know that the second term of the metaphor is BOSOM and not something else? As we can see, the bosom is not even visible in our picture, so how do we recover this concept from the image? Just relying on the picture we cannot say that what we have is a metaphor, because the second term (bosom, in our case) is not even hinted at. It is in fact thanks to the anchoring text "burger bra" that the metaphor is created. Applying Black's theory we can see that the similarity between the two terms is not pre-existent but, rather, is created with the aid of the textual context. As we know a bra is designed to provide women with an enhanced bosom. Thus, projecting that knowledge onto a burger we come to think of a burger as of a woman's bosom. Then, one of the correspondences is a projection from wearing a bra (in the case of a woman), to the use of a higher quantity of ingredients (in the case of burgers). Another correspondence is that the resulting shape, for both women and burgers, will be enhanced; the third correspondence is that the attraction increases; thus, the bosom of a woman will be more attractive to look at, and the burger more nutritious to be eaten.

A second point is: how do we know the metaphor is BURGER IS BOSOM and not BOSOM IS BURGER? In other words, what is the metaphor's literal A-term, the primary subject (PS, in Black's terminology), and what is its figurative B-term, the secondary subject (SS)? In our pictorial metaphor, as we lack the grammatical clues given in verbal metaphors, we need to take into account something else: context -the pictorial context-, plus world knowledge that we bring to bear (Fairclough, 1989). Thus, it is the viewer's awareness that the advertisement is for burgers rather than for breasts what guides their assignment of the PS as burger and the SS as bosom. In other words, it is the combination of the viewer classifying the picture as an advertisement plus the fact that they understand the verbal context that is responsible for the distribution of primary and secondary subjects. All this processing gives strength to the concept of situational context (Fairclough, 1989).

A third question is the matter of property transfer; that is to say, what property/properties get transferred, in Black's terminology, from the secondary subject (bosom) upon the primary subject (burger)? It seems quite clear that the message is: the new burgers, through the use of a bigger quantity of ingredients (more meat, double cheese and bacon) look more nutritious and possibly are. Thus, the properties projected are bigger shape and a more nutritious product.

Another important point to consider in this example is the relevance of the link established between the domains of appearance and flavour. We, as readers, work with the implication that the better something looks, the more palatable it is expected to be. Why is that so? Because we tend to assign a positive value judgment to big things over small ones; thus, BIG IS BETTER.

\subsection{AUDI Advertisement}

In this advertisement the pictorial element is accompanied with a higher number of words, which will trigger a more gradual exploitation of the image. 




Figure 2.

The next advertisement is a good example of how a metaphor can be achieved through the clever combination of the pictorial element and the verbal component. Just by looking at the foregrounded image - a number of musical (wind) instruments assembled in to some type of structure -, we do not have a clue of the message being conveyed. Thus, apart from the musical instruments, the other pictorial element given is the logo of Audi, the make of a car, which already sets the scene for the understanding of the image: the world of cars. Nevertheless, the information provided so far is not enough the grasp the message.

We need to pursue the analysis further by moving one layer up: the verbal message, which comes divided into three parts: the name of the brand, the headline and the body:

1. Name of the brand: Audi

2. The headline reads: "Nuevo Audi SE con motor TFSI de 265 CV. Potencia in crescendo".

3. The body reads: "Todo está listo para que comience una nueva interpretación de la más avanzada tecnología. Dirigida por el nuevo Audi S3..., capaz de desarrollar 265 CV perfectamente afinados... El resultado es intenso y palpitante... Nuevo Audi S3. Una sinfonía de emociones in crescendo.

By joining the pictorial element (musical instruments) with the verbal clues which point in the 
direction of a concert being performed, the domain of instruments is well established. The other term of the metaphor is suggested by the physical resemblance of the image to an engine plus the verbal clues which point in the direction of the domain of cars. Thus, at this point, the two terms of the metaphor, fused into one, have been made available: ENGINE and MUSICAL INSTRUMENTS. Nevertheless, through the mechanism of metonymy, each term of the metaphor can be seen to stand for something else. In the case of engine, we know that engines are the most representative parts of cars. Thus, the pictorial element conveying the image of an engine stands for the whole car being advertised (Audi S3). Likewise, instruments represent music.

The question that arises now is how to distribute the terms. Is it AUDI S3 IS MUSIC or MUSIC IS AUDI S3? In other words, what is the metaphor's literal A-term, the PS, and what is the metaphor's figurative B-term, the SS? World knowledge or the understanding that the advertisement is for cars rather than for music is what guides the viewer in assigning the distribution of the two terms: A for cars, B for music, which takes us back again to the important notion of situational context by Fairclough (1989). At this point we are able to verbalize the metaphor in the following way: AUDI S3 IS MUSIC. But, still, we can move one layer up by asking ourselves the functions of cars and music in our society. The answer is that cars are to be driven and music to be listened to. If we introduce this idea into the metaphor, the result is DRIVING THE AUDI S3 IS LISTENING TO MUSIC.

As for the property transfer, what properties are projected from the SS (music) to the PS (driving a particular car)? It is the product being advertised - or something that metonymically reflects the product, the engine, - that is the pictorially present PS of the metaphor. Transferred are the ideas of "refinement, elegance, softness, having a delicate taste and high technology" clearly setting the difference between driving this particular car and any other car.

\subsection{IPOD Advertisement}

The reason for the choice of this advertisement is similar to that of the first example provided where the pictorial element comes to full life through the presence of the short textual message.

The advertisements analyzed so far had one thing in common: only one of the terms of the metaphor was present in the image. By contrast, this new advertisement features both terms pictorially. Thus, we easily perceive the two terms of the metaphor as car and earphones, which is hinting, by way of metonymy, at the whole of the musical device, as will be seen.

Let us proceed, once again, to analyze this in different stages:

In Figure 3 we can see in the foreground a car, particularly a model of the make Volswagen (Golf), which comes with attached headphones. This advertisement, as the previous one, catches the viewer's attention easily because it is a deviation from convention as one would not expect to see a car at the other end of the earphones, but rather a music device such as an MP3. Thus, relying on the information available we seem to have access to the two terms of the metaphor: a model of the make Volkswagen, which is precisely the most popular model they manufacture (Golf), and earphones, which -very likely though it remains to be proved- stand metonymically for musical device. Besides, by way of physical resemblance, 
the winding shape of the earphones seem to suggest the road the car is supposed to be coming from. At any rate, we need to go further in this analysis for a full understanding of the message.

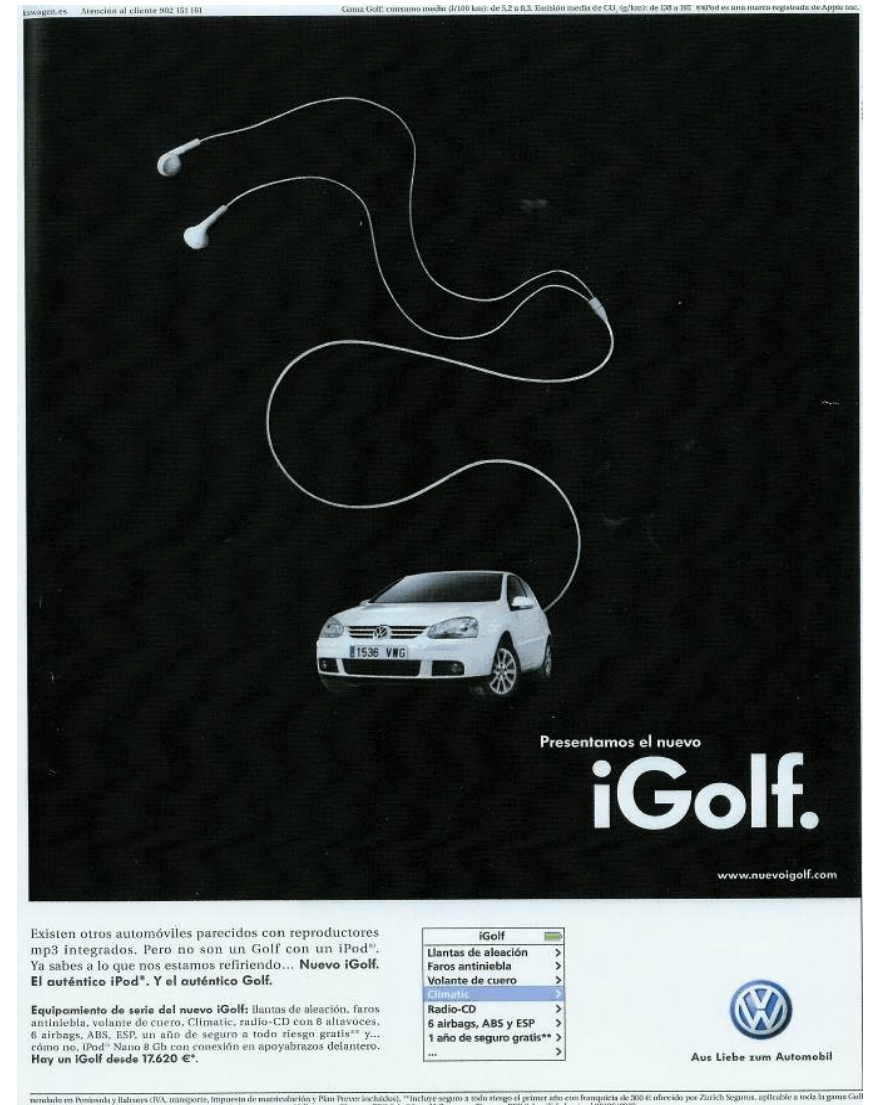

Figure 3.

If we invoke the verbal context, new and valuable information is activated:

1. As the headline we can read: "Presentamos el Nuevo iGolf".

2. In the body of the advertisement, we read: "Existen otros automóviles con reproductores integrados. Pero no son un Golf con un iPod. Ya sabes a lo que nos estamos refiriendo... Nuevo iGolf. El auténtico iPod. Y el auténtico Golf'.

The word iGolf, present in both the headline and the body, and written in bigger characters, gives us a clue as to the direction to follow since iGolf reminds us of the word iPod. Thus, the verbal component fulfills the function of anchoring the message conveyed by the picture by fusing the two words "Golf" and "iPod" into one "iGolf", exactly the same process depicted in the picture where the earphones and the car have been fused into one. This claim clearly reinforces the statement that the earphones simply a partial rendering of an MP3 player, specifically the Apple brand. Another ingredient which hasn't been mentioned yet is the colour of the car and of the earphones: white, which is the prototypical colour for an iPod.

As for the distribution of the terms, since the advertisement is for this type of car rather 
than for this type of MP3s, the direction of the metaphor establishes the Golf as the PS, and the iPod as the SS. Now the properties being projected from the domain of iPod to the domain of Golf, for which we need to invoke our world knowledge, can be phrased as style, elegance and fun.

At this stage of the analysis the global message is clear, with all the information provided pointing in the same direction, and the metaphor is unfolded clearly for the reader, who is invited to perceive a Golf as an iPod. The resulting metaphor is, then: GOLF IS AN iPOD, a clever combination of pictorial and verbal elements. As has been said above, the verbal component is indispensable to make sense of this pictorial metaphor. Again Black's creativity theory comes to the fore, as there is no pre-existent similarity between the two terms, but rather it is created through the use the pictorial metaphor and anchored by the verbal message.

\subsection{CONNECTA Advertisement}

This advertisement has been chosen because it is a less prototypical example of pictorial metaphor for the reasons that will be mentioned below.

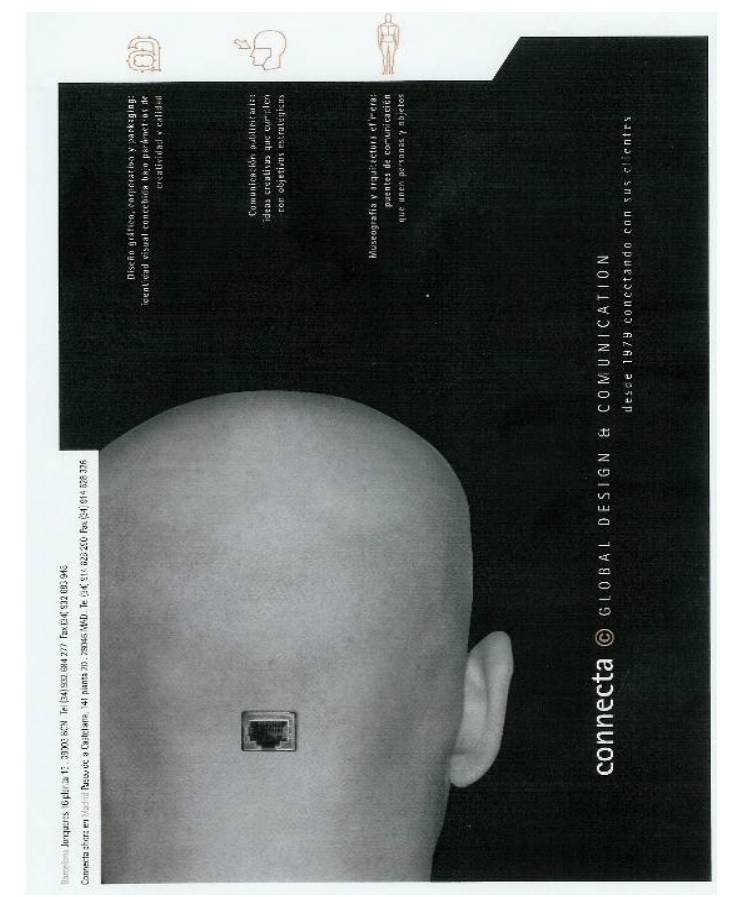

Figure 4.

In this advertisement, we can see a weird image: the back of somebody's head with an USB port built in. The placement of this port is a deviation from what is expected, as one would anticipate finding this type of specialized outlet on a computer rather than on a human head. In the example at hand, the same as in the Golf advertisement, both terms of the metaphor are suggested. Thus, we can easily recognize the human being, as one of the terms being represented metonymically by the picture of a head, and a computer, as the second term, 
through the metonymic representation of a USB port. Both terms have been only partially depicted.

In order to establish which of the terms is the PS and which is the SS, we need to look at the verbal message as the pictorial context does not help much. At this stage, the hypothetical verbalization of the metaphor would run along the lines A COMPUTER IS A HUMAN BEING or A HUMAN BEING IS A COMPUTER, but neither of them seems to make much sense in the given context. In fact, what is happening is that the agency advertising its services has created a loose associative link in which pictorial and verbal ingredients are cleverly combined. In other words, the message conveyed is: we, as an agency, offer the service of finding and connecting with clients in the outside world. As for the direction of the terms of the metaphor, it is difficult to assess the pictorial dominance of one domain over the other, but I tend to favour the dominance of the computer as the anchoring text is "connecta". Nevertheless, the message conveyed is not clear yet.

If we look at property transfer, there is no one clear property that is transferred from $\mathrm{B},(\mathrm{SS})$, to A, (PS). Since I am following Black, and the projection of elements from B upon A is an essential aspect of metaphor in his theory, I should conclude that this is not a metaphor. Rather, this advertisement seems to be a clever way of packing lots of information into two integrated images by applying our world knowledge.

\section{Discussion of advertisements}

Now that we have the global picture of all the advertisements, a number of comments applying to all can be made.

Firstly, a certain degree of similarity between the two terms of the metaphor is often involved either because it is natural and available at first sight or because it has been forced into the picture. Thus, in some cases, the terms of the metaphor representing the PSs have been assembled, folded or rearranged (examples of Figures 2 and 3 ) to force the physical similarity with the SS. This statement is in line with the claim made by Black when he says that the similarity is created rather than preexistent. There are other cases, though, where such similarity is largely absent or completely lacking (Figure 1), which entails that identification of the terms, direction of the projection and properties transferred will depend on the verbal component plus world knowledge.

Secondly, as regards the role that the verbal component plays in the understanding of each advertisement, its importance varies greatly. Thus, there are cases where the text is absolutely necessary to understand the message (anchoring text, in Barthes' terminology) (Figure 1); in other cases, what the text does is to reinforce the message already unfolded by the pictorial metaphor (Figure 3). It is also possible to come across examples -I do not have any in my small corpus- where the text could be left out and still the pictorial metaphor would stand on its own. A consequence that can be deduced from what has been said: the more dependent a pictorial metaphor is on the verbal component, the weaker that pictorial metaphor is and, possibly the more cognitive effort will be needed by the viewer in order to process it (each pictorial metaphor), although this hypothesis would be have to be tested. 
Since the working hypothesis for this paper was that the use of pictorial metaphor contributed to a more effective and visual transmission of a number of values promoted through advertising, let us look into each advertisement at the SSs chosen and at the properties projected from SS onto PS as that will determine the values enhanced as part of our society's upheld ideology. Thus, this analysis tries to unveil how the viewer is persuaded into adopting certain patterns of behaviour, through the promotion of those values which the viewer, theoretically, incarnates by the purchase of the product advertised.

In Figure 1 (Burger example), a new burger (PS) is presented in terms of a bosom (SS), which highlights values such as volume and appearance.

In Figure 2 (Audi example), driving an S3 (PS) is charged with the connotations of a symbolic activity (listening to music as the SS), which means that the physical properties of a car, represented pictorially by an engine, are promoted beyond the physical world by transmuting its inherent nature (an engine) into that of an orchestra. The values endorsed are those of softness and high tech.

In Figure 3 (iGolf example), where the car Golf (PS), a traditional and very popular car, is converted into a very much wanted object (iPod), through its novelty, as it is impregnated with a universe of connotations, which is the result of the sum of the symbolic value attached to both products: freedom, both to listen to the music you like and to take you wherever you want to go; style coming from the elegant design of both; and modernity, as both are cutting edge products.

In Figure 4 (Connecta example), it seems difficult to talk about the connotations embedded in this advertisement as there is no real property transfer between the two domains (human beings and computers) but rather the alienation of those two domains to be added up simultaneously as a way to package lots of information through just the depiction of an image.

\section{Conclusions}

As Lakoff and Johnson (1980) say metaphor is a matter of thought which is, then, reflected in language but also, as I expect to have shown, following Forceville (1994), in pictures. Thus, pictorial metaphor was the focus of this paper.

Advertising seems to be a fruitful area for the research of this topic since the cognitive mechanism of metaphor works very well in a field like this where there is a strong need to make the abstract as concrete as possible. Since most research on the topic of metaphor is connected to verbal metaphor, for this analysis I have relied on all the theory and concepts originating from those studies (notably Lakoff and Johnson, 1980; Black, 1993).

Through the analysis, it has become clear that when confronted with an advertisement, the viewer must process the information provided in the understanding that it is an advertisement, which implies that the ingredient of intentionality is always present, as well as the fact that a number of stages need to be covered to fully understand the message. Those stages, which move bottom up, follow a subsequent order: a) the pictorial context, which depicts the basic context the viewer will be working with; b) the linguistic message, which will help the viewer fix the intended meaning (anchoring function); c) and finally the world knowledge, which 
enriches the information put together so far by applying a wider context than that imposed by the pictorial metaphor. Each of those stages builds up on the previous one, so coherence must be kept throughout the process.

As seen in my small corpus, not all the advertisements are clear cases of metaphor, which implies that some defining criterion is needed to tell pictorial metaphors from non-metaphors. Although at first sight it might seem that having two domains necessarily leads into a metaphor, this has proved not to be the case (Figure 4), where in fact the presence of two domains just work as an effective way of wrapping up a lot of information together in one shot. On the other hand, the characteristic of property transfer, a key concept in this analysis, should be helpful when trying to identify a pictorial metaphor. Consequently, for future research, this will be the necessary condition to be met to differentiate pictorial metaphors from non-metaphors.

Finally, the reason why these advertisements have been selected is because of the intrinsic intentionality behind them, as has been pointed out above, which makes them appropriate for studying the persuasive nature of advertising language. Consequently, through the enhancement of certain values, such as those of freedom, style, modernity, volume, appearance, the favoured point of view of a given society is openly laid out, which imposes, up to a certain extent, some restrictions on its members by expecting certain prescribed patterns of behavior. Hopefully, these findings will shed some light on some of the persuasive techniques used in advertising.

\section{Notes}

1. Black's Interactive Theory does not only apply to the language of advertising. It has also been proved to be effective when dealing with sex-related metaphorical language (Crespo Fernández, 2008).

\section{References}

Barthes, Roland (1986): “The rhetoric of the image". In R. Howard, trans., The Responsibility of Forms. Oxford, England: Blackwell, 21-40 (Original work published 1964).

Black, Max (1993): “More about metaphor”. In A. Ortony, ed., Metaphor and thought. New York: Cambridge University Press, 19-41.

Crespo Fernández, Eliecer (2008): "Sex-related Euphemism and Dysphemism: An Analysis in Terms of Conceptual Metaphor Theory". Atlantis 30 (2): 95-110.

Lakoff, George and Mark Johnson (1980): Metaphors We Live by. Chicago: The University of Chicago Press.

. (1996): Moral Politics; what conservatives know that liberals don't. The University of Chicago Press. . (1999): Philosophy in the Flesh. Basic Books.

Fairclough, Norman (1989): Language and Power. London: Longman.

Forceville, Charles (1994): "Pictorial metaphor in advertisements". Metaphor and Symbolic Activity 9(1): 1-29. . (1996): Pictorial Metaphor in Advertising. New York: Routledge. 
Hausman, Carl (1989): Metaphor and Art: Interactionism and Reference in the Verbal and Nonverbal Arts. Cambridge: Cambridge University Press.

Hodge, Robert and Gunther Kress (1993): Language as Ideology. London: Routledge.

Kennedy, John (1982): "Metaphor in pictures". Perception 11: 589-605.

Ortony, Andrew (ed.) (1993): Metaphor and Thought. Cambridge: Cambridge University Press.

Richards, Ivor Armstrong (1971): The Philosophy of Rhetoric. New York: Oxford University Press. (Original work published 1936).

Whittock, Trevor (1990): Metaphor and Film. Cambridge: Cambridge University Press.

\section{Appendix}

Sources of advertisement illustrations:

\section{Figure 1}

Advertiser: Burguer King; Product: XXL; Advertising agency: Revolution;Title: "Burger Bra" - Control de Publicidad y Marketing. 2007. Año 46. Especial premios 06/07. Edipo, 18.

\section{Figure 2}

Advertiser: Audi; Product: Audi S3; Advertising agency: DDB; Title: "Motor"

- Control de Publicidad y Marketing. Anuario 2007. Edipo, 9.

\section{Figure 3}

Advertiser: Volkswagen; Product: Golf; Advertising agency: DDB; Title: "iGolf" - Control de Publicidad y Marketing. Anuario 2007. Número especial. Edipo, 63.

\section{Figure 4}

Advertiser: Connecta; Product: Global design and communications; Advertising agency: Connecta. - Control de Publicidad y Marketing. Anuario 2004. Número especial. Edipo, 49. 